ARTíCULOS 



\title{
PATRONES FORMALES E INTERPRETACIÓN: EL FUNCIONAMIENTO DE MÁS EN ESPAÑOL
}

\author{
José María Brucart \\ Universitat Autònoma de Barcelona. Centre de Lingüística Teòrica \\ josepmaria.brucart@uab.cat
}

\begin{abstract}
Resumen
Se estudia el funcionamiento sintáctico del operador aditivo más en español, tanto en su variante simétrica (dos más dos) como en la asimétrica (dos días más; más de dos días) y se propone un análisis unitario que derive este último valor de la proyección de ciertas categorías funcionales que permiten establecer una relación asimétrica entre los dos argumentos seleccionados por dicho operador. Se propone tratar las construcciones de más asimétrico como vectoriales y se argumenta a favor de incluir en este mismo grupo las comparativas de desigualdad. Si la propuesta es correcta, la idea de comparación que se asocia a tales construcciones sería una noción cognitiva derivada de un patrón formal más simple, de naturaleza vectorial (aditiva en el caso de más y sustractiva en el de menos).

PALABRAS CLAVE: construcciones aditivas, construcciones vectoriales, comparativas de desigualdad, comparación, categorías funcionales
\end{abstract}

\begin{abstract}
A unified analysis for the different uses of the additive operator más in Spanish is proposed, including the symmetric variant (dos más dos, 'two plus two') and the asymmetric one (dos días más, 'two more days'; más de dos días, 'more than two days'). The asymmetric variant is derived as a result of the projection of some functional categories establishing an asymmetric relation between the two arguments selected by the additive operator. Asymmetric más is analyzed as a vectorial construction and it is also argued that comparative constructions of inequality can be properly included in the same group. If the proposal is on the right track, the idea of comparison associated to these constructions would be a cognitive notion derived from a simpler formal pattern of vectorial nature (additive for más 'more' and subtractive for menos 'less').

KEY WORDS: additive constructions, vectorial constructions, comparatives of inequality, comparison, functional categories.
\end{abstract}

\section{Introducción}

La oposición entre forma y función ha sido siempre un núcleo de discusión muy activo en la teoría lingüística (Newmeyer, 1998; Mendívil Giró, 2003). Este trabajo incide en esta polémica, así como en otros centros de interés reciente en la teoría gramatical, tanto teóricos como empíricos. Entre los primeros figuran la noción de núcleo en sintaxis (Corbett, Fraser \& McGlashan (eds.), 1993), la proyección sintáctica de las piezas léxicas (Borer, 2005) y la composicionalidad del significa- 
do (Escandell Vidal, 2004). Entre los segundos, el funcionamiento sintáctico del operador aditivo más en español, el análisis de las construcciones comparativas de desigualdad, su relación con los esquemas vectoriales y las claves de la alternancia entre de y que como introductores del segundo término de la comparación ${ }^{1}$.

El enfoque teórico que se adopta a lo largo del trabajo es formal, en consonancia con el de la gramática generativa, que es el marco que se usará para el análisis, pero se intentarán subrayar los puntos de contacto y las diferencias con otras teorías de carácter funcionalista. En particular, el objetivo del trabajo es el siguiente: (a) presentar un análisis unificado de las construcciones aditivas encabezadas por el operador más, (b) defender el carácter composicional de las construcciones comparativas y (c) abogar por una versión exoesquelética o neoconstruccionista de las proyecciones léxicas en la sintaxis, en línea con las propuestas de Borer (2005).

\section{Los diferentes usos de más en español}

Si hubiera un concurso para elegir las palabras con mayor versatilidad sintáctica en español, es probable que el adverbio más figurara entre los candidatos con mejor puntuación. Nuestro interés se centrará en los cuatro usos que se ejemplifican en (1). Se coloca en redonda el sintagma formado por el operador aditivo:

(1) a. Tus libros más los míos formarán una gran biblioteca (más aditivo simétrico)

b. La reparación duró una semana más de las dos previstas (más aditivo asimétriсо)

c. Lee más libros que novelas (más comparativo)

d. Hace dos años la empresa ganó 10 millones y el año pasado 8 más

Conviene señalar que (1d) es ambigua. En una de sus interpretaciones, el beneficio de la empresa el año pasado fue de 18 millones. En tal caso, el valor de más es el aditivo asimétrico, como en (1b). En la otra interpretación, la empresa ganó el año pasado solamente 8 millones. Este es otro valor de más: el de alteridad.

Pese a que son suficientes para mostrar la variedad de construcciones en los que más participa, los ejemplos anteriores no agotan las posibilidades sintácticas del operador más. Por lo menos pueden mencionarse otras dos construcciones en las que entra esta unidad:

1 Versiones previas de este trabajo fueron presentadas en el XI Congreso de la Sociedad Argentina de Lingüística (celebrado en Santa Fe el 12-4-2008), en las XI Jornadas de Estudios de Lingüística: Investigaciones Lingüísticas en el s. XXI (Alicante, 13-3-2009) y, en colaboración con Ángel J. Gallego, en el IV Nereus International Workshop (Bellaterra, UAB, 10-10-2008). Agradezco las observaciones y comentarios que se me formularon, que han permitido mejorar la argumentación. La investigación se ha beneficiado de la ayuda financiera de un proyecto del MEC (Microvariación en la estructura oracional, HUM2006-13295-C02-02) y de una ayuda a grupos de investigación de la Generalitat de Catalunya (2009SGR1079). 
(2) a. Luis es el que ha hecho más esfuerzos por integrarse de todos nosotros (más superlativo)

b. Entiende a Debussy, mas no le gusta Beethoven (más adversativo)

Es cierto que la norma ortográfica del español distingue este último valor de todos los demás por la falta de tilde en el más adversativo, pero parece claro que el valor originario de esta unidad no es esencialmente distinto del de los demás casos hasta aquí considerados: su valor aditivo queda reflejado en que, dejando aparte la adversatividad que introduce, existe la posibilidad de conmutarlo por la conjunción copulativa y: Entiende a Debussy y no le gusta Beethoven. Nótese que las condiciones de verdad de esta última oración son idénticas a las de $(2 b)^{2}$.

El considerable elenco de usos del más español se pone igualmente de manifiesto en el hecho de que en una lengua como el inglés no existe una unidad léxica que pueda cubrir todas las variantes señaladas. En tal lengua sería necesario recurrir nada menos que a cinco unidades distintas: plus (1a), more (1b-d), most (2a), other (1d) y but (2b).

En este trabajo limitaremos nuestra atención a los usos aditivos de más que se representan en los ejemplos de (1) y sólo de modo muy esporádico aludiremos a los que aparecen en (2). Lo que tienen en común todos los usos de más en (1) es su carácter de operador aditivo que suma dos magnitudes ${ }^{3}$. Como ya se ha señalado, (1d) admite dos interpretaciones: la propiamente aditiva y la de alteridad. Esta última es equivalente a la que se expresa por medio de otro:

\section{Hace dos años la empresa ganó 10 millones y el año pasado otros 8}

Lo característico de la interpretación de alteridad de (1d) es que en tal caso más se comporta como un marcador presuposicional discursivo de naturaleza aditiva que se usa para transmitir la instrucción de que la magnitud seleccionada es un registro que se debe poner en paralelo con alguna otra instancia de la misma clase mencionada previamente en el discurso o perteneciente al trasfondo informativo de los interlocutores. Se trata, por lo tanto, también de un operador aditivo, pero su rango de actuación atañe al discurso, por lo que no queda afectado el contenido proposicional de la oración en la que aparece, de modo que su eliminación no implicaría cambio alguno respecto de las condiciones de verdad del enunciado. Por el contrario, en la otra interpretación de (1d), es necesario sumar dos cantidades para obtener el beneficio

2 Lo que no significa, como ya se ha dicho, que el contenido de ambas sea idéntico, ya que (2b) incorpora una implicatura convencional de naturaleza adversativa que está ausente en (2a). Sobre la noción griceana de implicatura convencional, véase Horn (1996).

3 En línea con lo que se propone en Brucart (2003), defenderemos la naturaleza aditiva del más comparativo. La mayoría de los estudios gramaticales tienden a segregar este valor del propiamente aditivo (cfr. Gutiérrez Ordóñez, 1994a,b). 
de la empresa correspondiente al segundo año $(8+10)$. Una diferencia importante entre ambos operadores es el carácter proposicionalmente monádico del operador de alteridad, frente a la naturaleza diádica del resto de los usos aditivos.

Lógicamente, el uso de alteridad de más no está al alcance de menos, que como operador sustractivo sí que admite el resto de las construcciones de (1). Por lo tanto, (4) sólo acepta la interpretación de operador diádico, de manera que el beneficio de la empresa el pasado año fue de dos millones:

(4) Hace dos años la empresa ganó 10 millones y el año pasado 8 menos

En este trabajo nos centraremos en el funcionamiento del operador aditivo más, pero todo lo que de él se diga es igualmente de aplicación al operador sustractivo menos.

Nuestra argumentación seguirá dos estadios principales. El primero consiste en estudiar la relación entre la variante simétrica y la asimétrica del operador aditivo con el objeto de proponer un análisis para ambos tipos de construcción. Luego se intentará trasladar ese mismo análisis a las comparativas de desigualdad. El supuesto básico que adoptaremos es que todos los usos ejemplificados en (1) tienen mucho en común y que el hecho de que el español no presente la distinción entre plus/ more o minus/ less no es una mera coincidencia. El hecho de que el inglés lexicalice de manera diferente muchas de esas variantes no implica que las correspondientes estructuras no compartan un conjunto importante de rasgos en común. En particular, propondremos que en todos los ejemplos de (1) más funciona como un operador aditivo diádico. En el análisis, adoptaremos un enfoque neoconstruccionista o exoesquelético de la relación entre el léxico y la sintaxis (Borer, 2005). Desde esta perspectiva, la polisemia que muestran muchas piezas léxicas, tal como sucede con más en español, es la consecuencia de las distintas configuraciones sintácticas en las que tales unidades pueden participar.

Los diferentes usos de las construcciones aditivas y sustractivas del español han sido extensamente estudiados en la bibliografía, en trabajos como Gutiérrez Ordóñez (1994a), desde el estructuralismo funcionalista, y Sáez del Álamo (1997), en el marco generativo. La idea de que las comparativas de desigualdad pueden analizarse como una variante particular de las construcciones aditivo-sustractivas se propuso por vez primera en Brucart (2003). Más recientemente, Gallego \& González (2005) han elaborado esta idea en una propuesta diferente de la que se presentará aquí.

\section{El más simétrico}

Para analizar las diferentes construcciones de (1) es necesario, en primer lugar, distinguir dos variantes de esta unidad: el más simétrico de (1a), que corresponde al inglés plus, y el asimétrico o vectorial de los demás ejemplos, equivalente al inglés more. 
La función que desempeña el más simétrico es similar a la que caracteriza al operador aditivo $y$. De hecho, las gramáticas tradicionales tienden a considerar que este uso de más es conjuntivo. Una característica común con la conjunción copulativa por excelencia es la reversibilidad de sus argumentos, como en (5):

(5) Dos más cuatro son seis $=$ Cuatro más dos son seis

Pero no es menos cierto que las diferencias entre más e $y$ son considerables. Así, el más simétrico ve restringida su capacidad combinatoria a los elementos que denotan individuos (sintagmas determinantes y cuantificacionales), frente a la conjunción $y$, que puede unir cualquier otro tipo de entidades (proposiciones, propiedades, predicados y adjuntos). Eso deriva de la naturaleza intrínsecamente aditiva de más, cuyos argumentos deben denotar cierta magnitud (ya sea número o cantidad) sobre la que actúa el operador:

(6) a. La sentencia le obligó a pagar un millón de indemnización más las costas

b. Investigan la combinación de flúor más calcio en 180 pacientes

Otra diferencia viene dada por el hecho de que más sólo tiene capacidad para combinarse con dos argumentos, restricción que no comparte con $y$ :

(7) a. *Dos, cuatro más seis son doce

b. Dos, cuatro y seis son doce

c. Dos más cuatro más seis son doce

En (7c) la adición de tres componentes es posible por la presencia de dos operadores aditivos, que funcionan recursivamente, dando lugar las estructuras de (8), semánticamente equivalentes, dada la propiedad asociativa de la suma. Nótese que en ambos casos se respeta escrupulosamente la naturaleza diádica del operador aditivo:

(8) a. [dos más [cuatro más seis]]

b. [ [dos más cuatro] más seis]

Una última diferencia entre ambas unidades viene dada por el hecho de que los sintagmas encabezados por el más simétrico imponen una lectura conjuntiva (colectiva o de grupo) de sus argumentos, mientras que, como es bien sabido, $y$ acepta interpretaciones de grupo y distributivas. Por lo tanto, sólo en (9b) se puede estar hablando de dos bibliotecas distintas, formadas respectivamente por el conjunto de entidades denotado por cada uno de los miembros de la coordinación:

(9) a. Tus libros más los míos formarán una gran biblioteca (No ambigua: sólo una gran biblioteca [interpretación conjuntiva]) 


\section{b. Tus libros y los míos formarán una gran biblioteca}

(Ambigua: una biblioteca [int. conjuntiva] o dos [int. distributiva])

Parece lógico atribuir las diferencias que se acaban de señalar a la naturaleza estrictamente aditiva de más, frente a la meramente copulativa de $y$. En cuanto a la estructura de las proyecciones formadas por el más simétrico, supondremos que es la que se refleja en (10), donde el operador aditivo selecciona dos argumentos $\mathrm{SD}$ (eterminante) o $\mathrm{SCu}$ (antificador) en la posición de complemento y especificador, tal como Kayne (1994: 12) propone para la conjunción copulativa:

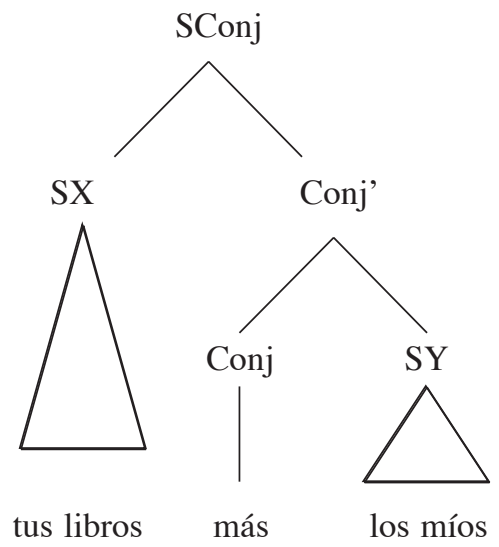

Como ya se ha dicho, los argumentos de (10) son conmutables. No obstante, es importante señalar que, desde el punto de vista del embalaje informativo, el elemento que recibe mayor prominencia prosódica es el argumento SY, que ocupa la posición de complemento. Esto puede derivarse de la interacción de las dos variantes de la Regla de Acento Nuclear propuestas para el español en Zubizarreta (1998), dado que tal constituyente es el más bajo tanto en el orden de mando-c asimétrico como en el orden selectivo ${ }^{4}$.

\section{El más asimétrico y las construcciones vectoriales}

Pasemos ahora a estudiar las variantes asimétricas del más aditivo. Es con mucho el valor más frecuente de este operador. De hecho, cuando es la única uni-

\footnotetext{
4 En general, se supone que la posición de complemento se relaciona más directamente con el núcleo que la posición de especificador. Este contraste se aplica en toda clase de construcciones sintácticas y sirve, por ejemplo, para distinguir la relación que mantiene con el verbo el argumento interno de la que caracteriza al argumento externo. Así, en una oración transitiva, se supone que el argumento interno (complemento directo) forma con el verbo un constituyente, mientras que la relación de este último con el argumento externo (sujeto) es de segundo orden: [El atleta [ganó una medalla]].
} 
dad con realización fonética de la correspondiente proyección, sólo es posible la interpretación asimétrica, como se ve en (11a). Tal situación es predecible, dada la naturaleza conjuntiva del más simétrico, en oposición a la que desempeña en los ejemplos de (11), tomados de Brucart (2003:17). Como es bien sabido, la gramática tradicional caracteriza estos últimos como usos adverbiales. Una característica importante que nos interesa resaltar de las construcciones de (11) es que, pese a las diferencias superficiales que se dan entre ellas, todas son realizaciones de un único patrón sintáctico. La diferencia se limita al carácter explícito o implícito de los dos argumentos seleccionados por más, que independientemente de su realización fonética, están siempre presentes en la interpretación semántica de estas oraciones. Como ya se ha dicho, en (11a) ninguna de las dos magnitudes seleccionadas por el operador aditivo asimétrico aparece con realización fonética, pero la única manera de interpretar esta oración consiste en suponer que a una cierta duración previamente establecida se ha de añadir algún lapso de tiempo adicional para calcular la duración de las conversaciones. En $(11 \mathrm{~b}, \mathrm{c}, \mathrm{d})$ sólo uno de los argumentos de más se presenta como elíptico. Finalmente, en (11e) ambos argumentos aparecen realizados fonéticamente ${ }^{5}$ :

(11) a. Las conversaciones durarán más.

b. Las conversaciones durarán más días.

c. Las conversaciones durarán dos días más.

d. Las conversaciones durarán más de dos días.

e. Las conversaciones durarán dos días más de los cuatro inicialmente previstos.

Como se observa en los ejemplos de (11), el más asimétrico establece entre sus dos argumentos una asimetría que tiene como correlato formal la aparición de la preposición de ante el complemento. Las características principales del más asimétrico pueden resumirse del siguiente modo, tal como se presentan en Brucart (2003):

5 La variante de (11e), con realización fonética de los dos argumentos de más, es importante para el análisis de estas oraciones, puesto que es el eslabón que muestra que todas las realizaciones de (11) corresponden a un único esquema sintáctico. No obstante, conviene señalar que se trata de la variante menos frecuente en el uso asimétrico, debido a que el complemento que aparece precedido de la preposición de debe denotar una magnitud que pertenezca al trasfondo informativo, por lo que frecuentemente se elide. Nótese que en (11e), ese elemento tiene que ser definido $(*$ dos días más de cuatro). En tal posición podrían aparecer también, por ejemplo, relativas de valor cuantitativo introducidas por el artículo determinado (dos días más de los que pensábamos). La operación aditiva de cálculo que más representa no sólo implica cierto coste en términos de procesamiento, sino que también puede suscitar falta de adecuación pragmática a las máximas conversacionales formuladas por Grice (1975): resulta mucho más cooperativo decir Tardaré cuatro días que Tardaré dos días más dos. Eso explica que las variantes asimétricas sean mucho más frecuentes que las simétricas, porque en aquellas se rompe el paralelismo entre las dos magnitudes, de manera que la segunda se interpreta como cantidad básica a la que se añade un diferencial: algo más de dos días. 
(12) Características del más asimétrico

a. Selecciona dos magnitudes y las suma. Una de ellas funciona como base (precedida de la preposición de) y la otra funciona como diferencial.

b. Tanto la base como el diferencial pueden aparecer implícitos. Cuando eso sucede, el contenido de la base se recupera discursivamente (por medio de un antecedente o a través de la información compartida) y el del diferencial se interpreta como una cantidad inespecífica cuya magnitud se interpreta en proporción a la de la base.

c. La base funciona como fondo informativo y el diferencial como figura. En general, el grado de especificidad de la base no puede ser inferior al de la figura (cf. Se necesitan dos ingenieros más de $\{l o s / * u n o s\}$ que han venido).

d. El más asimétrico da lugar a una construcción vectorial. Un vector es una magnitud que consta de un punto de aplicación, una dirección y un sentido. En este caso, el punto de aplicación es la base (que a su vez es una magnitud), el diferencial es la magnitud añadida y la dirección y el sentido del vector corresponden al operador aditivo. La diferencia entre más y el operador sustractivo menos estriba en que, a pesar de que ambos tienen la misma dirección, corresponden a sentidos opuestos.

Nos interesa resaltar la naturaleza vectorial de las construcciones asimétricas encabezadas por más. La idea de asociar contenido vectorial a ciertas construcciones lingüísticas no es nueva en los estudios gramaticales. Bull (1960), un influyente estudio sobre la temporalidad y el aspecto verbal en español, analiza los tiempos verbales como vectores que se orientan a partir de un punto de origen ${ }^{6}$. También en las construcciones que expresan medida aparece nítidamente el esquema vectorial, con diferencial y base, formando sintagmas adverbiales o preposicionales (dos días antes del concierto, dos kilómetros a la izquierda del monumento) o esquemas oracionales (Hacía dos meses del accidente, Faltaban dos meses para las vacaciones) ${ }^{7}$.

Las construcciones de más asimétrico o vectorial presentan restricciones adicionales a las que caracterizan a su contrapartida simétrica, como muestra el contraste entre la buena formación de (9) y la agramaticalidad de sus correlatos vectoriales:

$$
\begin{aligned}
& \text { a. *Tus libros más de los míos formarán una gran biblioteca } \\
& \text { b. *Oxígeno más de hidrógeno da agua }
\end{aligned}
$$

6 La intuición aparece ya en Bello (1841), quien propone interpretar los valores de los tiempos verbales en función de tres primitivos relacionales (coincidencia, anterioridad y posterioridad). Los dos últimos son de naturaleza vectorial, aunque este término no aparece, lógicamente, en la obra del gramático venezolano. Parece claro que el sistema de Bello influyó profundamente en la propuesta de Bull. Cf. también Rojo (1974) para un tratamiento de la temporalidad del español basado en supuestos similares.

7 El interés por el estudio de las construcciones vectoriales en la gramática generativa se ha incrementado considerablemente en los últimos tiempos, sobre todo a partir de Zwarts (1997) y Zwarts \& Winter (2000). 
La diferencia deriva de la naturaleza vectorial del esquema asimétrico, frente al carácter conjuntivo del simétrico. Mientras que los conjuntos que se suman en este último caso pueden definirse extensionalmente (de manera idéntica a la coordinación copulativa), la construcción vectorial impone que sus miembros representen una magnitud (cantidad o número), requisito que no se cumple en (13). También actúa sobre estas oraciones un requisito de conmensurabilidad, de modo que las magnitudes que entran en la operación aditiva deben corresponder al mismo tipo de entidad. Se pueden sumar manzanas con manzanas (tres manzanas más de las que tengo yo), pero no manzanas con peras (*tres manzanas más de las peras que tengo $y o$ ). No obstante, esta última restricción no afecta a las construcciones comparativas cuya base aparece introducida por que, ya que en tal caso es posible poner en relación magnitudes pertenecientes a dos escalas distintas (tres manzanas más que las peras que tengo yo; más manzanas que peras). Como se estudiará en el $\S 8$, esta es una de las diferencias fundamentales entre de y que en estas construcciones.

\section{El análisis del más vectorial}

Una cuestión que se suscita en cuanto se intenta analizar el más vectorial es la de la relación de éste con la variante simétrica estudiada en el $\S 3$. Se trata, en definitiva, de determinar si existe algún estadio derivacional común entre ambos o, por el contrario, se trata de dos unidades meramente homónimas, que dan lugar a representaciones sintácticas separadas desde el principio. En nuestra opinión, hay un argumento básico para postular un estadio derivacional común para ambas representaciones: en los dos casos se trata de un operador aditivo que selecciona dos magnitudes. La diferencia estriba, por lo tanto, en el carácter vectorial de la construcción que el más asimétrico proyecta. Podemos representar la diferencia como en (14), donde el más asimétrico tiene todos los rasgos que caracterizan a la variante simétrica, pero a ellos añade otros adicionales que son los responsables de su naturaleza vectorial:

(14) más simétrico

a. operador aditivo

b. binario más asimétrico

a. operador aditivo

b. binario

c. vectorial

Un aspecto interesante que se deduce de la diferencia entre ambas construcciones es que, en los casos en que ambas construcciones son compatibles, no queda afectada la semántica proposicional del enunciado, sino la manera como se presenta el embalaje informativo. Así, las dos oraciones de (15) coinciden en sus condiciones de verdad, pero divergen en la manera como se realizan los dos argumentos del operador: 
(15) a. Las obras duraron los diez meses previstos más quince días.

b. Las obras duraron quince días más de los diez meses previstos.

En las formulaciones más recientes del programa minimista dentro del generativismo se ha prestado especial atención a lo que podríamos denominar "doble articulación semántica de las lenguas naturales".

En palabras de Chomsky (2005: 8),

C-I [Conceptual-Intentional] interface incorporates a dual semantics, with generalized argument structure as one component, the other one being discourse-related and scopal properties. Language seeks to satisfy the duality in the optimal way [...], $\mathrm{E}$ (xternal) M(erge) serving one function and I(nternal) M(erge) the other ${ }^{8}$.

Es obvio que la distinción que estamos estudiando afecta a ese segundo nivel de la representación semántica al que se refiere el texto anterior, que incorpora las propiedades relacionadas con el discurso. De hecho, una tendencia dominante en el estudio de la gramática generativa desde la formulación del modelo de principios y parámetros ha sido la de proponer proyecciones funcionales capaces de acoger fenómenos no relacionados directamente con la selección de argumentos, sino con elementos como la temporalidad, el aspecto, la modalidad, la polaridad, el foco, la cuantificación, la determinación, entre otros fenómenos en el ámbito de la oración.

Esta es la estrategia que seguiremos para reflejar las diferencias entre los dos tipos de más: defenderemos que las construcciones de más asimétrico presentan proyecciones funcionales adicionales cuya función es crear un contraste entre las dos magnitudes seleccionadas por el operador aditivo. Para ello adaptaremos el análisis vectorial propuesto en Svenonius (en prensa) para dar cuenta de la estructura de ciertos sintagmas preposicionales de naturaleza espacial del inglés, que modifica ligeramente propuestas anteriores de Zwarts (1997) y Zwarts \& Winter (2000). En concreto, supondremos que las diferencias sintácticas que presenta el más asimétrico derivan del proceso de legitimación de los rasgos vectoriales que lo caracterizan, de manera que las dos magnitudes seleccionadas por el operador aditivo experimentan un traslado a la posición de especificador de sendas proyecciones funcionales, que etiquetaremos SFondo y SFigura. Finalmente, la proyección más alta de la construcción vectorial es un Sintagma de Trayectoria (STray) que hospeda la magnitud diferencial que caracteriza a estos sintagmas. La línea discontinua muestra el área que corresponde a la estructura del más simétrico, que reflejamos

8 La interfaz C-I (conceptual-intencional) incorpora una semántica dual, con estructura argumental generalizada como uno de sus componentes, siendo el otro las propiedades relacionadas con el discurso y con el ámbito [de cuantificadores]. El lenguaje trata de satisfacer esta dualidad de manera óptima [...], atendiendo el ensamble externo una función y el ensamble interno la otra. [trad. JMB]. Las nociones de ensamble externo e interno se presentarán más adelante (cfr. la nota 13). 
anteriormente en (10) ${ }^{9}$. El árbol de (16) refleja la derivación sintáctica del esquema vectorial, que en sus primeras etapas es común con la de la variante simétrica ${ }^{10}$ :

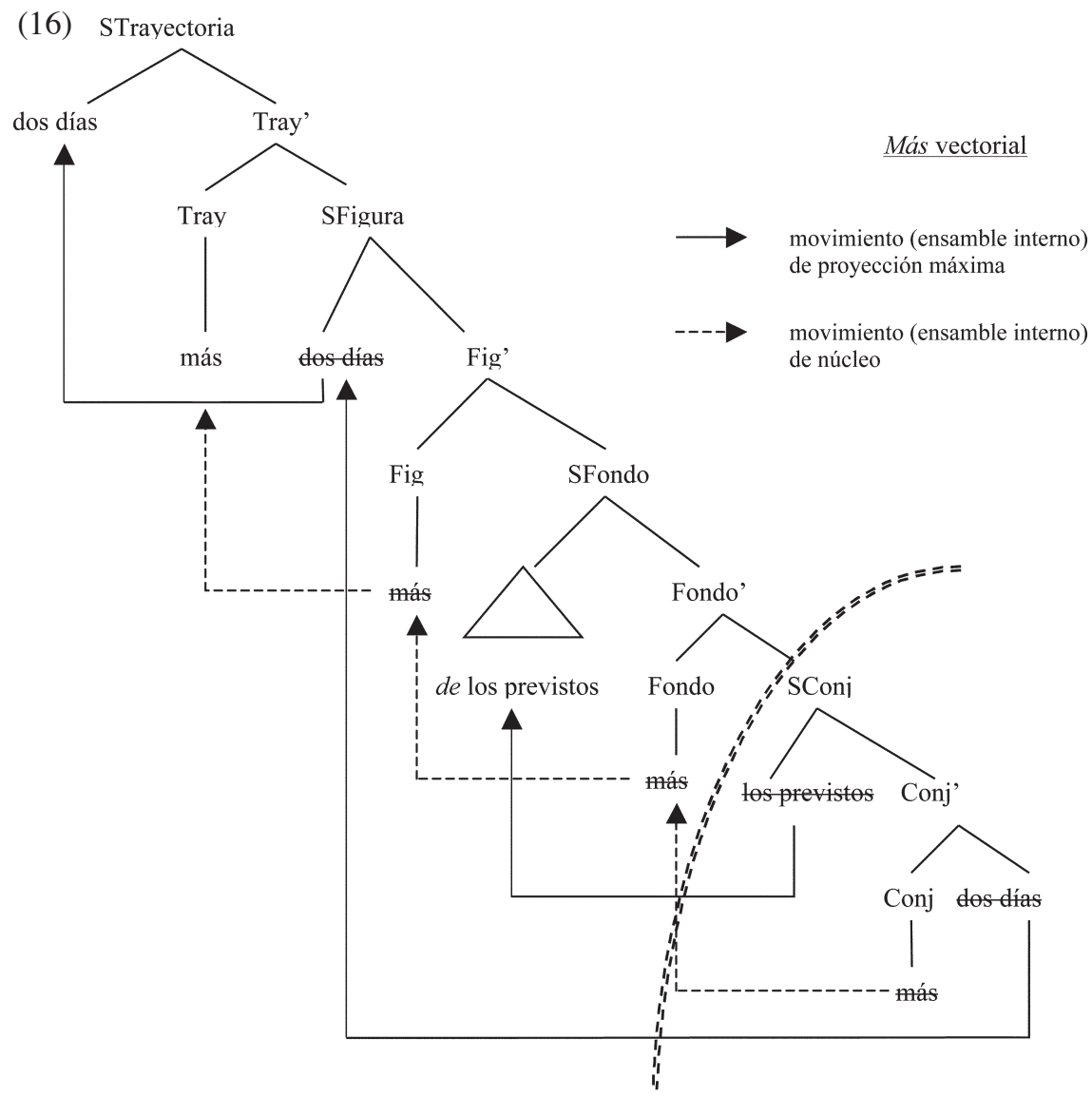

9 Es importante señalar que las dos listas de rasgos que se presentan en (14) tienen únicamente una función descriptiva y no significan que se conciban ambas variantes de más como piezas léxicas distintas. En línea con los enfoques neoconstructivistas, supondremos que hay una única instancia de más en español para las dos usos que nos ocupan. Que la estructura vectorial se proyecte sintácticamente o no dependerá de la existencia en la correspondiente representación sintáctica de las proyecciones funcionales que dan lugar a la ruptura de la simetría entre los dos argumentos del operador aditivo. Por lo que respecta al conjunto de rasgos que caracterizan a más, tenemos que suponer que es el que aparece en la lista más amplia representada en (14). Si las proyecciones funcionales vectoriales se realizan sintácticamente, el correspondiente rasgo de más será activado. Si no, la estructura que se generará será la simétrica y los rasgos de vectorialidad del operador aditivo quedarán inactivos en la sintaxis. 10 Las flechas que aparecen en el diagrama representan los diversos movimientos que se producen en la derivación de (16). Siguiendo la convención adoptada en la teoría minimista, en las posiciones desde las que se produce el movimiento hemos colocado una copia del elemento desplazado. De cada uno de los elementos que se han movido, sólo la copia más alta en el árbol se realiza fonológicamente, por lo que todas las demás aparecen tachadas. 
Hay algunos aspectos de la estructura de (16) que merecen comentario. En primer lugar, hemos etiquetado SFondo y SFigura lo que Svenonius (en prensa) representa respectivamente como Place Py GoalP. El motivo de ello es que, a diferencia de los SSPP espaciales, que son los que se estudian en ese trabajo, los argumentos de las construcciones aditivas no denotan lugares físicos, sino magnitudes. Por otra parte, es conveniente reiterar que el desencadenante de que la estructura compleja representada en (16) se proyecte es la presencia en la numeración ${ }^{11}$ de la correspondiente oración de los núcleos funcionales que, una vez proyectados, funcionan como elementos tractores de los movimientos que se producen en esa estructura. Si tales núcleos funcionales no están presentes en la numeración, la estructura asimétrica no se proyectaría y la única construcción posible sería la de la variante simétrica.

Un aspecto potencialmente problemático de la representación de (16) es la inserción del marcador preposicional de, que no aparece en la construcción simétrica, en la posición de especificador de SFondo. Supondremos que esta operación es consecuencia de la existencia de una relación de concordancia de rasgos entre la posición de núcleo del SFondo y su especificador, como procedimiento que introduce en la derivación la asimetría entre los dos argumentos del operador aditivo dando origen a la construcción vectorial. Se podría argüir, en contra de esta idea, que no es frecuente que se inserte una preposición derivacionalmente. Pero tal fenómeno no es totalmente inédito, ya que el proceso que estamos postulando es similar a la aparición del marcador de genitivo sajón en John's car, donde John se origina en la posición de complemento de car y asciende al especificador del SDet. En esa posición, se afija al marcador genitivo (siguiendo el análisis propuesto entre otros por Giorgi \& Longobardi, 1991).

Otra posible crítica a la inserción tardía de de consistiría en argumentar que eso supone una violación del Principio de proyección ${ }^{12}$, dado que su complemento o término se fusiona o ensambla inicialmente en la posición de especificador de la proyección más baja (el SConj). Sin embargo, se pueden oponer dos contraargumentos a esta crítica. Se podría abogar por las teorías que aceptan que el papel temático correspondiente a un argumento puede vincularse a alguna posición asociada al movimiento de aquél, como se propone por ejemplo en Bošković \& Takahashi (1998) con respecto al scrambling y en Hornstein (2001) en relación con la reflexivización. No obstante, no es preciso recurrir a supuestos tan extremos a la hora de justificar el caso que nos ocupa: el movimiento al especificador del SFondo no tiene consecuencias desde el punto de vista de la teoría temática, ya que el elemento que

11 En el modelo minimista, el término numeración se usa para referirse al conjunto de material léxico de todo tipo, incluidas las categorías funcionales que entran en la derivación sintáctica de una oración. En Brucart, Gavarró \& Solà (2007) se ofrece una presentación breve de ese modelo. Para una introducción más extensa a la misma teoría, véase Eguren \& Fernández Soriano (2004).

12 En los modelos generativistas, el Principio de proyección es el mecanismo que prohíbe la modificación de las propiedades de los elementos léxicos una vez se han incorporado a una derivación sintáctica. 
experimenta ensamble interno es el argumento externo del operador aditivo y el motivo de tal traslado está relacionado con la semántica discursiva y no con la proposicional: el objetivo es establecer la asimetría entre argumentos que caracteriza a la construcción vectorial. De hecho, podría concebirse la preposición como un mero marcador de caso. Un efecto importante de la preposición de en estas construcciones es el de valorar el rasgo de fondo de su término, de manera que este queda desactivado sintácticamente y no puede ejercer ningún efecto de interposición sobre el subsiguiente ascenso del otro argumento a la posición del especificador del SFigura. Que sea el argumento externo de más el elemento que represente el fondo en la construcción asimétrica es coherente con su papel de elemento menos prominente del operador aditivo en términos del embalaje informativo de la oración, tal como se ha argumentado en el $\S 3$.

Un último aspecto controvertido en la estructura de (16) es que contiene diversas capas funcionales con traslado iterado de núcleo a núcleo del operador asimétrico. Algunos autores (entre ellos, Chomsky, 2001) han indicado que el tradicional movimiento de núcleos debe tratarse como una operación fonológica, ya que carece de importe semántico. Sin embargo, resulta evidente que en este caso el movimiento del operador aditivo tiene lo que Harley (1995) denomina "sabor" o cariz semántico, ya que cada etapa del proceso se relaciona con una parte específica del patrón aditivo asimétrico y tiene efectos sobre la estructura informativa de la construcción. Para evitar el problema de contraciclicidad que arrostra el movimiento de núcleo ${ }^{13}$, Donati (2006) propone concebir tal operación no en términos de adjunción de núcleo, tal como lo hemos representado en (17a), sino como resultado del ensamble del núcleo en la raíz de la estructura, como en (17b). Esta última cumple escrupulosamente la Condición de extensión, ya que $\mathrm{Y}^{\circ}$ en este último caso da lugar a una nueva proyección, a diferencia del anterior:

\section{(17) (Donati, 2006)}

a.

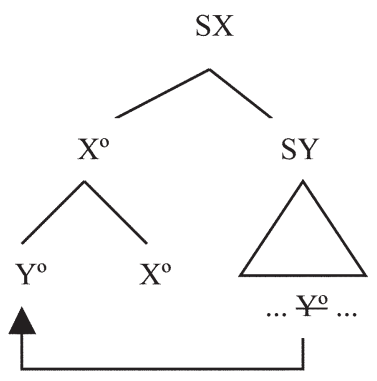

b.

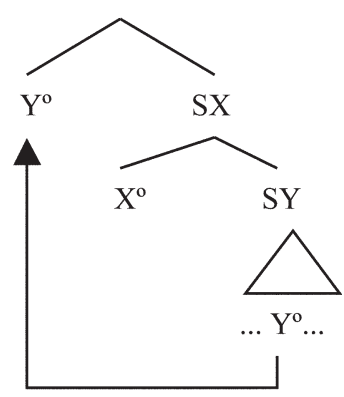

13 En el modelo minimista, la operación sintáctica que permite crear estructura es el ensamble o fusión (ing. merge). La operación de ensamble se aplica siempre entre un núcleo y un no núcleo y da lugar a una proyección sintáctica más compleja que la inmediatamente precedente. La derivación sintáctica procede de abajo arriba. En el caso de (16), por lo tanto, la primera proyección que se ensambla 
El resultado de la operación de ensamble interno sería validar un rasgo no interpretable en el núcleo funcional $\mathrm{X}^{\mathrm{o}}$. Es decir, que los procesos de traslado que crean la estructura asimétrica son el resultado del funcionamiento de mecanismos de validación de rasgos no interpretables contenidos en los sucesivos núcleos funcionales de las proyecciones SFondo, SFigura y STrayectoria. Podemos concebir estos procesos transformacionales como casos particulares del esquema de (17b). Eso implicaría que en el núcleo de las proyecciones funcionales señaladas se sitúa originariamente una preposición relacional abstracta cuyos rasgos no interpretables deben validarse mediante el ascenso del operador aditivo. Si se opta por este análisis, la estructura de (16) debería modificarse levemente para reflejar el ensamble interno sucesivo de más con la raíz de cada núcleo funcional situado por encima del SConj ${ }^{14}$.

Un argumento a favor de postular la presencia de preposiciones abstractas en el núcleo de las proyecciones funcionales situadas por encima de SConj lo sugiere el hecho de que en algunos casos tal unidad pueda aparecer incorporada al operador aditivo. Eso es lo que ocurre en español con la locución de más, que sólo admite una magnitud que expresa una cantidad que sobrepasa la que se considera necesaria o conveniente:

(18) a. Compró [ diez entradas más de las necesarias ]

b. Compró [ diez entradas de más (*de las necesarias)]

Como muestra el par mínimo anterior, el ensamble morfológico (en el sentido de Matushansky, 2006) de más con la preposición de bloquea en este caso la realización fonética de la magnitud que se toma como fondo, de modo que en esta construcción sólo es posible expresar el diferencial. La noción de cantidad por exceso que se asocia a éste deriva probablemente del hecho de que el fondo implícito se interpreta como la magnitud que corresponde a la cantidad por defecto -esto es, la prevista o necesaria-.

es la del SConj y posteriormente, paso a paso, se proyecta el resto de la estructura. El ensamble puede ser externo, cuando uno de los dos elementos que se fusionan entra en la derivación por vez primera (es decir, procede directamente de la numeración). Las operaciones de movimiento se conciben en el modelo minimista como un caso de ensamble interno, de manera que un elemento de la estructura ya formada se reensambla con esta dejando una copia en la posición que ocupaba originariamente. Las operaciones de ensamble siempre tienen que expandir la estructura por la raíz del árbol -es decir, por su parte superior-. El problema que plantea el movimiento de más en (16) es que para que se produzca el ensamble interno del operador aditivo es necesario que se haya ensamblado el núcleo funcional correspondiente. Esta segunda operación violaría la Condición de extensión, porque no provocaría la expansión del árbol por su parte superior.

14 Una alternativa a la propuesta de Donati (2006) se presenta en Matushansky (2006). En este trabajo el movimiento de núcleo se concibe como una operación sintáctica que puede ir seguida de un proceso de ensamble morfológico entre el elemento movido y el núcleo de la proyección funcional receptora. 
También el francés muestra explícitamente la preposición en las construcciones aditivas y comparativas, como se muestra en los ejemplos de (19), obtenidos a través del buscador Google:

(19) a. Les hommes fument en moyenne 15 cigarettes par jour soit seulement 2 de plus que les femmes.

'Los hombres fuman una media de 15 cigarrillos al día, o sea solamente 2 más que las mujeres' (www.doctissimo.fr/html/sante/mag_2001/mag1214/ sa_4855_cancer_vessie.htm)

b. Les hommes ont deux heures de temps libre en plus que les femmes pendant le week-end.

'Los hombres tienen dos horas más de tiempo libre que las mujeres durante el fin de semana' (www.lsp-mas.be/mas/archives/2005/03/08/femmes.html)

c. Si vous complétez votre $S U 700$ avec un peu de mémoire vive (jusqu'à soixante quatre MB en plus des quatre d'origine)...

'Si Ud. completa su SU700 con un poco de memoria RAM (hasta 64 MB además de los cuatro de origen)...' (www.macmusic.org/articles/view.php/ lang/fr/id/39/)

No trataremos de analizar en detalle el funcionamiento de estas construcciones en francés, pero parece posible concluir que la preposición que precede inmediatamente al operador aditivo es la instanciación de alguno de los núcleos funcionales reflejados en (16): es probable que de esté ligada a Fondo $^{\circ}$, mientras que en se asocie con Figura $^{\circ}$. La existencia en español de más, de más (de donde proceden el adjetivo demás y el adjetivo-adverbio demasiado) y además va en la misma dirección. Nótese que en este último caso la preposición $a$ puede asociarse al STrayectoria, cuyo especificador queda bloqueado en esas construcciones, mientras que la realización del SFondo es posible:

(20) a. Compró [ diez entradas más de las necesarias]

b. Compró [diez entradas de más (*de las necesarias)]

c. Compró diez entradas, además de las necesarias

Un modo de captar la relación que parece existir entre las diversas variantes que incluyen el operador aditivo más consiste en adoptar los presupuestos de la morfología distribuida (Halle \& Marantz, 1994) e interpretar las distintas variedades como lexicalizaciones de los rasgos correspondientes a los distintos núcleos funcionales. De este modo, se consigue un análisis unitario del fenómeno, frente al enfoque atomístico que supondría partir de entidades léxicas diferenciadas desde la numeración. De hecho, ese mismo problema se plantea con los dos valores de más que acabamos de analizar (el simétrico y el asimétrico). En este caso, la generalización se obtiene partiendo de la idea de una sintaxis en la que los núcleos funcionales son los que establecen las diferencias entre las distintas variedades de una pieza léxica, frente al enfoque atomístico de los análisis propiamente proyeccionistas. 


\section{La interpretación de la base y del diferencial}

Como refleja (11a) [Las conversaciones durarán más], una característica notable del más asimétrico es la posibilidad de que tanto la base como el diferencial aparezcan sin realización fonética. Dado que ambos componentes son necesarios para interpretar la construcción aditiva, en tales casos la información que no se ofrece explícitamente debe recuperarse de algún modo. Esto se logra por medio de dos estrategias diferentes. En primer lugar consideraremos el caso de la base, que puede aparecer implícita, como en (11a-c). Como se indica en (12b), la información correspondiente a esta debe extraerse del discurso previo, como en (21a) o, incluso, del contexto situacional, como en (21b):

(21) a. Las conversaciones durarán más (=11a)

b. ¿Desea algo más?

Svenonius (en prensa) nota que algunos núcleos locativos del inglés, como below 'debajo', legitiman un complemento nulo que se interpreta en el sentido de "allî", en oposición a beside 'al lado, junto a', que no lo admite ${ }^{15}$ :

(22) Svenonius (en prensa)

a. We stood on a bridge. Below (it) we could see barges laden with port wine. 'Estábamos en un puente. Debajo (de él) podíamos ver barcazas cargadas de oporto'

b. I saw a small house. Beside *(it) was a gas pump.

'Vimos una casita. Junto *(a ella) había un surtidor de gasolina'

El análisis que propone este autor para los casos de complemento implícito es el que se representa a continuación ${ }^{16}$ :

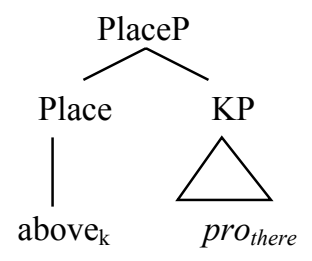

15 Para reproducir en español la asimetría de (21) podría recurrirse al contraste entre al lado y junto. La primera admite la omisión fonética del complemento, mientras que la segunda lo requiere.

16 Svenonius (en prensa) considera que SK es una proyección cuya función es la de asignar caso al complemento del núcleo locativo. 
Svenonius señala que los elementos que tienen la posibilidad de legitimar un elemento locativo nulo son precisamente los que seleccionan sintagmas de medida. Esta correlación funciona igualmente en el caso de las construcciones que estamos estudiando. Así, las comparativas de igualdad, que no aceptan diferencial, no admiten la presencia de una base de comparación nula, excepto cuando se da un patrón prosódico de suspensión, que desencadena una interpretación intensiva, no comparativa:
a. Luis es $(10 \mathrm{~cm}$.) más alto (que Antonio)
b. Luis es $(* 10 \mathrm{~cm}$.) tan alto $*$ (como Antonio)
c. Luis es tan alto...

Nos referiremos ahora a las distintas posibilidades de realización del diferencial en estas construcciones. En el análisis que hemos propuesto, la función de este elemento es triple: es un argumento del operador aditivo, corresponde a la figura en el esquema asimétrico y se interpreta como diferencial en toda la construcción. Sus posibilidades de realización son diversas, según muestra la alternancia de (25):
a. Leyó más
diferencial nulo, restrictor de clase nulo
b. Leyó más libros
diferencial nulo, restrictor en $\{$ Esp, SFig $\}$
c. Leyó bastantes más libros
d. Leyó bastantes libros más
dif. en $\{$ Esp, STr $\}$, restrictor en $\{$ Esp, SFig $\}$
diferencial y restrictor en $\{$ Esp, $\operatorname{Tr}\}$

Los esquemas de (26) reflejan las diferencias estructurales del diferencial de los anteriores ejemplos (el símbolo $\varnothing$ indica que el correspondiente elemento no tiene realización fonética):
a. $\left[_{\mathrm{STr}} \varnothing\left[_{\mathrm{Tr}}\right.\right.$ más $\left[_{\mathrm{SFig}} \oslash\left[_{\mathrm{Fig}}\right.\right.$, más $\ldots$
b. $\left[_{\mathrm{STr}} \varnothing\left[_{\mathrm{Tr}}\right.\right.$ más $\left[_{\mathrm{SFig}} \emptyset\right.$ libros $\left[_{\mathrm{Fig}}\right.$, más ...
c. $\left[_{\mathrm{STr}}\right.$ bastantes $\left[_{\mathrm{Tr}}\right.$, más $\left[_{\mathrm{SFF}}\right.$ bastantes libros $\left[_{\mathrm{Fig}}\right.$, más $\ldots$
d. $\left[_{\mathrm{STr}}\right.$ bastantes libros $\left[_{\mathrm{Tr}}\right.$ más $\left[_{\mathrm{SFig}}\right.$ bastantes libros $\left[_{\mathrm{Fig}}\right.$, más ...

La distribución de los datos de (26) puede resumirse en el siguiente sumario:

(27) a. Más siempre se proyecta al núcleo del sintagma funcional más alto (STr).

b. El cuantificador, sea nulo o fonéticamente explícito, siempre se sitúa en el especificador de STr.

c. Cuando el cuantificador del diferencial es nulo, no arrastra al restrictor hasta la proyección más alta, por lo que este queda en el especificador de SFig.

d. Si el cuantificador tiene realización fonética, arrastra al restrictor hasta el especificador de STr, excepto en el caso de los cuantificadores evaluativos (bastante, mucho, poco), que pueden aparecer desgajados de su restrictor. 
A la vista de los datos de (27), cabe preguntarse por el motivo del doble comportamiento de los cuantificadores imprecisos. Sáez del Álamo (1997) vincula esta particularidad al hecho de que los cuantificadores que pueden elevarse sin el restrictor son $\mathrm{SCu}$ son precisamente aquellos que tienen la capacidad de funcionar como atributos, como muestra el contraste entre 20 libros son bastantes y $* 20 \mathrm{li}$ bros son algunos). Es probable que esta característica esté ligada a la condición de adjetivos evaluativos del primer grupo ${ }^{17}$. Sáez del Álamo (1997) propone atribuir a ambas subclases una estructura diferente: los evaluativos forman una proyección propia, situada en el especificador del correspondiente $\mathrm{SCu}$, mientras que el resto se insertan en la posición de núcleo de esa misma proyección. Eso explicaría que, a la hora de ascender al especificador de STr, los cuantificadores evaluativos pudieran ir acompañados o no de su restrictor. En el primer caso cualquiera de las dos proyecciones máximas $\mathrm{SCu}$ es susceptible de traslado, de lo que deriva la alternancia descrita en (27c). Por el contrario, los cuantificadores existenciales no evaluativos, sujetos a la estructura de (28b), deberían ir acompañados siempre de su restrictor, ya que no componen por sí solos una proyección máxima:

(28) (Sáez del Álamo, 1997)
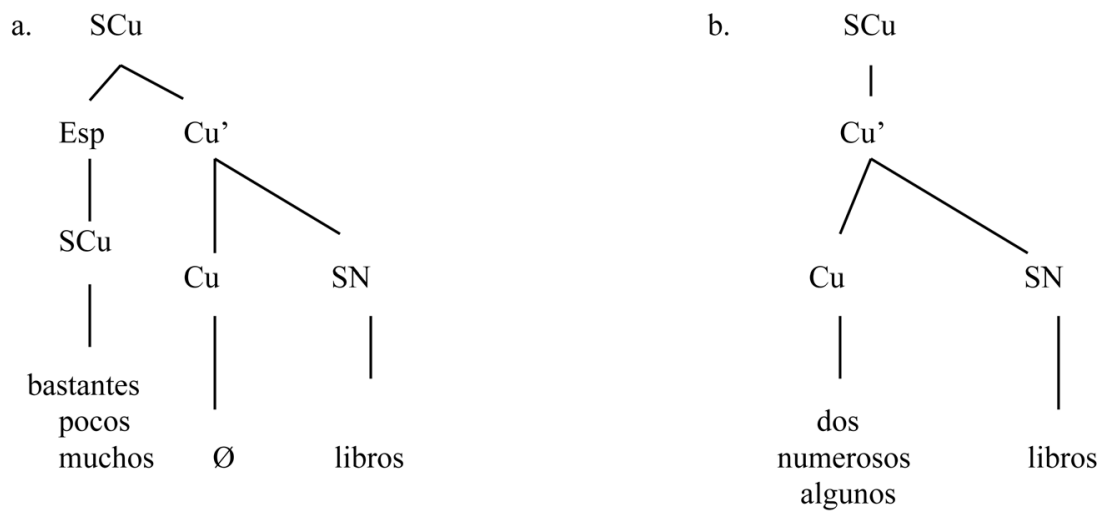

17 De hecho, los cuantificadores que estamos denominando evaluativos admiten dos interpretaciones: la propiamente evaluativa y la cardinal proporcional. La diferencia entre ambas se observa en un mensaje publicitario como Un poco de Magno es mucho, donde el atributo recibe interpretación evaluativa, lo que permite que la proposición no sea contradictoria. Los datos del CORDE atestiguan hasta el siglo XX usos esporádicos de algún asimilables a los de los cuantificadores evaluativos: Y bien pudieran darme ustedes algún más alimento (Benito Pérez Galdós, Torquemada y San Pedro). Y también como atributo: [...] a usted, señor pretendiente por alto, o más bien por bajo medio, sírvale de escarmiento lo pasado, y si sus merecimientos y servicios son algunos, hágalos conocer por los medios que la razón y el honor aprueban (Ramón de Mesonero Romanos, Escenas de 1832 [Panorama matritense (primera serie 1832-1835)]. Es probable que en estos casos algún se interprete como un evaluativo equivalente a 'suficiente'. 
Parece haber diferencias entre los sustantivos contables y los no contables a efectos de la operación de ascenso que estamos comentando: la subida en solitario del cuantificador es mucho más frecuente cuando el restrictor es un nombre no contable. El siguiente cuadro corresponde a una consulta efectuada a la base de datos CREA de la RAE el 4 de marzo de 2008:

Ascenso del cuantificador y clases de nombres en el restrictor

\begin{tabular}{|c|c|c|}
\hline SUSTANTIVO & mucho más $N$ & mucho $N$ más \\
\hline personas & 19 & 5 \\
\hline cosas & 97 & 119 \\
\hline años & 23 & 102 \\
\hline problemas & 13 & 1 \\
\hline votos & 6 & 0 \\
\hline gente & 57 & 8 \\
\hline agua & 6 & 0 \\
\hline alimento & 2 & 0 \\
\hline fuerza & 23 & 0 \\
\hline información & 25 & 0 \\
\hline sangre & 4 & 0 \\
\hline
\end{tabular}

Es probable que entre muchas más personas y muchas personas más medien diferencias de contenido: sólo la segunda permite una interpretación específica:

(30) a. Yo incluiría en la lista muchas más personas

b. Yo incluiría en la lista (a) muchas personas más

En (30a) se sugiere incluir en la lista un número mayor de personas (interpretación inespecífica). Esa misma lectura es posible en (30b), pero tal oración admite también la interpretación específica, aquella en la que el hablante tiene en mente a unas personas determinadas. Los datos del cuadro de (29) son compatibles con esta idea, porque los sustantivos no contables rechazan habitualmente la interpretación específica. Sea como fuere, es obvio que esta diferencia no sirve por sí sola para explicar el fenómeno, puesto que los cuantificadores numerales cardinales permiten la interpretación específica o inespecífica de su proyección, pese a lo cual sólo admiten el patrón $C u+N$ más.

\section{Las comparativas de desigualdad como construcciones vectoriales}

En varios momentos de nuestra argumentación hemos dado por supuesto que las construcciones comparativas de desigualdad son un caso particular del patrón asimétrico estudiado hasta aquí. Como este no es, ni mucho menos, el supuesto dominante sobre esta clase de construcciones, que tienden a ser interpretadas como esquemas de 
cuantificación relativa sobre escalas, dedicaremos este apartado a justificar la idea de que el esquema formal que sirve para formar las comparativas de desigualdad es el mismo que caracteriza a las construcciones aditivas estudiadas hasta ahora.

La tradición gramatical ha identificado diversos componentes en las oraciones comparativas: la magnitud comparada (que puede ser un número, una cantidad o un grado), la entidad o propiedad comparada (que es el restrictor de la magnitud), los dos términos de la comparación y el operador comparativo (que indica la igualdad o desigualdad entre los términos):

(31) Juan ha leído más novelas que María

magnitud comparada: número

entidad comparada: novelas

términos de la comparación: Juan y María

operador comparativo: más

complemento comparativo o coda: el elemento encabezado por que o de.

Las entidades comparadas pueden coincidir con los términos de la comparación, como en Luis ha leído más novelas que ensayos. Existe también la posibilidad de que las entidades o propiedades comparadas sean varias, como en Juan ha leído más novelas que ensayos ha escrito María, donde se establece un doble contraste entre Juan y María y entre novelas y ensayos.

En la caracterización precedente falta un último constituyente característico de las comparativas de desigualdad: el diferencial, que, como muestran los ejemplos de (32), puede aparecer tanto en las comparativas propias (cuya coda está encabezada por que) como en las comparativas relativas (con coda encabezada por de):

(32) a. Juan ha leído tres novelas más que María

b. Juan ha leído tres novelas más de las que María le recomendó

c. La mesa es $10 \mathrm{~cm}$ más alta que el taburete

d. La mesa es $10 \mathrm{~cm}$ más alta de lo que me dijeron

De hecho, la existencia de un diferencial es una característica indisoluble de la comparación de desigualdad. Que frecuentemente quede implícito no representa ninguna particularidad, dado que eso mismo sucede en las construcciones aditivas estudiadas previamente. Por lo tanto, parece que las construcciones comparativas de desigualdad reproducen el esquema vectorial: la coda es el fondo y el diferencial (que incluye la entidad comparada) es la figura. Un argumento adicional a favor de este enfoque lo constituye el hecho, detectado por Gutiérrez Ordóñez (1992: 528), de que la presencia de la coda comparativa es incompatible con la de otro sintagma que ejerza la misma función de fondo:

(33) a. *Compró más de cien libros que Andrés

b. Compró más de cien libros más que Andrés 
La gramaticalidad de (33b), con dos complementos que representan el fondo se debe a la presencia de dos operadores aditivos, cada uno de los cuales legitima un fondo propio: que Andrés es la base del segundo más, mientras que de cien libros más que Andrés lo es del primero.

Así pues, en las comparativas de desigualdad, la magnitud atribuida a uno de los argumentos de la oración se obtiene a partir de otra que se expresa (implícita o explícitamente) en lo que tradicionalmente se ha llamado segundo término de la comparación y que se toma como base, añadiéndole una cantidad o grado adicional (el diferencial). La noción de comparación deriva del hecho de que la magnitud expresada en el segundo término o base se obtiene del interior de una proposición, lo que permite atribuir la misma propiedad a algún otro argumento, a diferencia de las construcciones aditivo-sustractivas no comparativas, en las que ambas magnitudes se asignan directamente al mismo individuo. El esquema de (34) refleja la situación que estamos describiendo:

\section{Goliat mide 1,20 m. más que David}

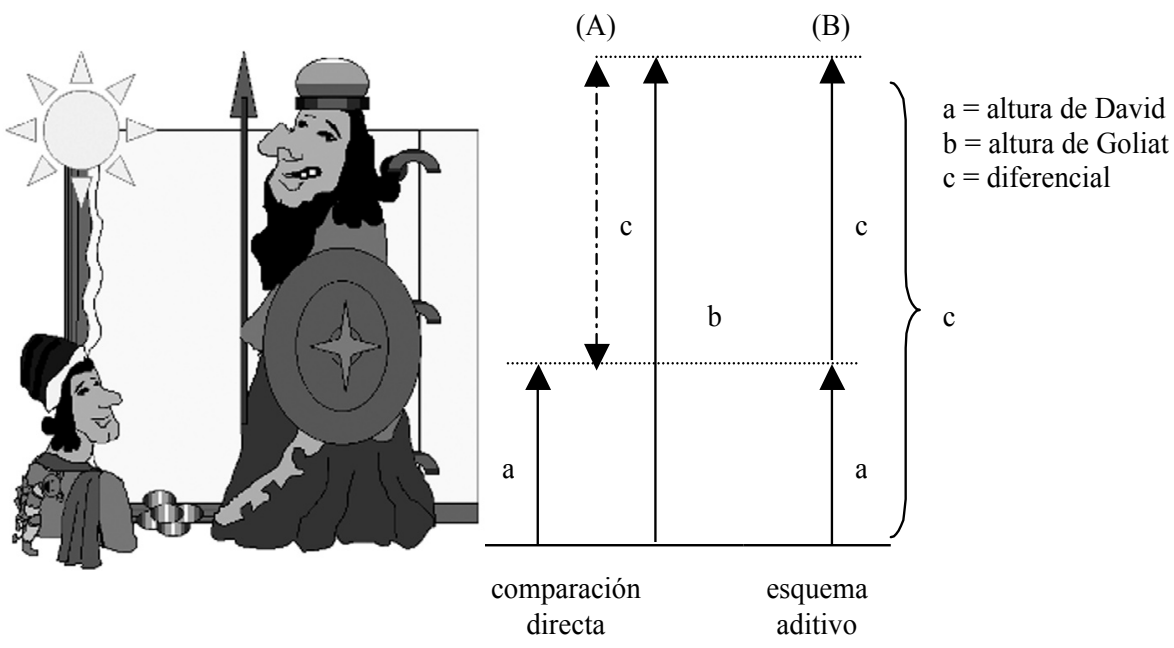

Los dos gráficos que aparecen a la derecha del dibujo corresponden a dos maneras distintas de poner en relación las tres magnitudes representadas. En el de (A), las alturas de David y Goliat se toman como primitivos a partir de los cuales se obtiene el diferencial entre ambas $(b-a=c)$. A primera vista, este es el esquema que corresponde más apropiadamente a la noción cognitiva de "comparación", ya que se ponen en contraste las respectivas magnitudes comparadas y, de su observación, se deduce el desajuste que media entre ambas ${ }^{18}$. En el de (B), en cambio, las magnitudes

18 Es probable que nuestra capacidad visual haya influido poderosamente en el hecho de que cognitivamente tendemos a interpretar la comparación en términos del esquema de (A) y no en el de 
que se toman como primitivas son la altura de David y el diferencial. De su suma se obtiene composicionalmente el tercer valor: la altura de Goliat. Una ventaja evidente del análisis que estamos proponiendo es que refleja de modo directo la aportación informativa de la oración, que toma como fondo la altura de David y como figura la de Goliat, precisamente la magnitud que se calcula a partir de las otras dos.

Un hecho bien contrastado en los estudios de tipología linguística es la considerable diferencia interlingüística que muestran los patrones de las oraciones comparativas (Stassen, 1985; Andersen, 1983; Hoecksema, 1984). De hecho, sin movernos del español, es posible observar que existe la posibilidad de expresar comparaciones a través de patrones sintácticos distintos:
a. Luis habla tres lenguas y María cuatro
b. Luis habla ruso y María no
c. Prefiero mil veces la música de Chopin a la de Satie
d. Llegó a la meta a tres segundos del ganador
e. La diferencia de altura entre las Torres Petronas y el Empire State Building es de sólo $3 \mathrm{~m}$

Una pregunta obvia que se desprende del análisis vectorial de las construcciones comparativas de desigualdad que estamos defendiendo es cómo se obtiene la idea de comparación que se asocia cognitivamente a este patrón de construcciones. Nuestra propuesta consiste en suponer que la noción de comparación se obtiene por implicación semántica a partir de la estructura vectorial aditiva. En efecto, si el cálculo de la altura de Goliat en (34) se obtiene mediante la suma de la altura de David más un diferencial, es obvio que esa magnitud es superior a la que corresponde a Romeo.

Frecuentemente se ha argumentado desde modelos como el de la gramática cognitiva que las oraciones comparativas aportan un argumento en favor de una visión no composicional del significado. Cuenca \& Hilferty (1999: 68), por ejemplo, señalan que la relación de implicación antonímica que se da entre las oraciones de (36) no puede atribuirse al significado individual de un adjetivo como alto, que es graduable y no absoluto:
a. Mari Loli es más alta que Enriqueta
b. Enriqueta es más baja que Mari Loli

\begin{abstract}
(B). En efecto, (A) es más icónico, porque toma como elementos primitivos las dos magnitudes que corresponden a los dos individuos objeto de comparación y deriva la tercera, cognitivamente más compleja, de la diferencia entre ellas. Que las lenguas naturales recurran con mucha frecuencia al esquema aditivo-sustractivo para vehicular la comparación de desigualdad constituye un argumento a favor de la autonomía de la forma respecto de la función y avala la tesis de la autonomía de la sintaxis. Si nuestro análisis va en la buena dirección, la noción de "comparación" no sería un primitivo gramatical, sino que derivaría de un patrón constructivo más básico.
\end{abstract}


Pero el problema sólo se presenta si se supone que el núcleo de la construcción comparativa es el adjetivo alto. En nuestro análisis, en cambio, es el operador aditivo más la unidad que selecciona las dos magnitudes que sirven para calcular la tercera. La relación coimplicativa entre las dos oraciones de (36) queda de este modo directamente reflejada, como se desprende de la fórmula de (37):

$$
\left[\mathrm{A}_{\mathrm{ML}}=\mathrm{A}_{\mathrm{E}}+\mathrm{DIF}\right] \quad \Leftrightarrow \quad\left[\mathrm{A}_{\mathrm{E}}=\mathrm{A}_{\mathrm{ML}}-\mathrm{DIF}\right]
$$

\section{El análisis de las codas comparativas y la alternancia entre que y de}

En el análisis que estamos proponiendo, las codas comparativas ejercen la función de magnitud representativa del fondo. Sin embargo, la forma que presentan no es tan transparente como la correspondiente a su contrapartida en las construcciones aditivas no comparativas, por lo que resulta conveniente revisar su funcionamiento. La bibliografía sobre las comparativas suele distinguir entre las comparativas relativas, cuya coda está encabezada por una preposición de que precede inmediatamente a una relativa de naturaleza cuantificativa -como en (38a)- y las comparativas propias, con coda encabezada por que -como la de (38b)-. Son estas últimas las que ofrecen mayor dificultad de análisis, dado que presentan unas posibilidades de variación mucho mayores:

(38) a. Luis ha dado cuatro clases más de las que María le pidió (que diera)

b. Luis ha dado cuatro clases más que \{María / conferencias/ el año pasado\}

En las comparativas relativas, de selecciona una relativa cuantificativa, como las estudiadas en Plann (1982, 1984), Bosque (1984) y Brucart (1993). Estas construcciones se caracterizan por el hecho de que el elemento relativo recibe una interpretación equivalente al relativo cuanto. Eso explica que dicho elemento no pueda aparecer en singular cuando la entidad comparada es contable, ya que en tal caso la interpretación de la relativa no sería cuantificativa, sino individuativa. Cuando el elemento singular es un sustantivo no contable, la restricción no se aplica porque tales nominales admiten interpretación cuantificativa:

(39) a. Luis vio más películas $\{q u e / * d e\}$ la que María le recomendó

b. Luis vio más películas \{quel de\} las que María le recomendó

c. Bebió más cerveza \{quel de\} la que era conveniente

Nótese que, con la base introducida por que, (39a) no es propiamente una oración comparativa, sino una aditiva de alteridad, como prueba la posibilidad de construir una paráfrasis con otras: Luis vio otras películas, además de la que María le recomendó. Que la oración no pueda interpretarse como una comparación deriva del hecho de que la coda introducida por que no contiene ningún elemento cuantificativo, algo imprescindible en las comparativas. En cambio, las construcciones de alteridad aceptan bases referenciales (no cuantificativas, por lo tanto). Gutiérrez Ordóñez 
(1994a) señala que una oración como Tuvo más novias que María es ambigua. En una interpretación, la oración es comparativa y la coda que María denota el conjunto de individuos que han sido novios de María. En la otra, se trata de una aditiva de alteridad. En ese caso, la coda refiere únicamente a 'María', de modo que la interpretación es que, además de María, el sujeto de la oración ha tenido otras novias. Así pues, pese a adoptar forma idéntica, las dos codas presentan diferencias muy importantes. En las aditivas de alteridad, la suma se efectúa entre un elemento definido extensionalmente y un diferencial cuantitativo. Eso explica el contraste entre *Tuvo esa novia más que María, con diferencial y coda referenciales, y Tuvo más que esa novia o Tuvo varias novias más que esa, con diferencial cuantitativo y base referencial. Por lo tanto, la aparición de que como introductor de la coda en las oraciones aditivas de alteridad se relaciona con la naturaleza semántica de la propia coda, ya que de impone siempre en estas construcciones un complemento cuantificativo.

Así pues, la preposición de que introduce la coda de las comparativas relativas se combina obligatoriamente con una relativa cuantificativa. Eso no representa ningún cambio con respecto a los fondos de las construcciones aditivas introducidos por esa misma preposición. Como ya se ha visto, su término debe recibir también una interpretación cuantificativa. El contraste de (40) reproduce la asimetría observada en las comparativas relativas. La primera oración admite únicamente una interpretación de alteridad ("además de esa, vio otras dos películas"), porque el demostrativo en singular no da pie para una interpretación cuantitativa, que es obligatoria en las comparativas, y la segunda admite la presencia de la preposición de porque el sintagma lo imaginable puede interpretarse cuantificativamente.

(40) a. Luis vio dos películas más \{quel *de\} esa

b. Luis ha visto más cine de lo imaginable

Como es sabido, el plural admite, a diferencia del singular, una doble lectura: referencial o individuativa y cuantitativa. Eso explica la ambiguiedad de una oración como He visitado más museos que esos. En la lectura de alteridad, la coda recibe una interpretación individual y denota un conjunto concreto de museos. Pero también es posible la interpretación comparativa, ya que esos, por su forma plural, puede recibir una lectura cardinal cuantificada y referir a un cierto número de museos. Cuando la coda está formada por una relativa sin antecedente expreso, la oración también puede recibir una interpretación cuantitativa o individuativa. En tales casos, la alternancia entre que y de es posible en la lectura comparativa ${ }^{19}$ :

(41) a. Vio más películas de las que le recomendaste (interpretación cuantitativa) b. Vio más películas que las que le recomendaste (interpretación individuativa [de alteridad] o cuantitativa [comparativa])

19 (41a) puede recibir también una interpretación partitiva, pero esa lectura no tiene relevancia para lo que aquí se discute. 
La oposición entre de y que no sólo se pone de manifiesto en las oraciones comparativas, sino que se observa igualmente en las construcciones aditivas con fondo no oracional:

(42) a. Aquel día compró más de un ordenador

b. Aquel día compró más que un ordenador

(43) a. No llevaba (*nada) más de 20 euros en el bolsillo

b. No llevaba (nada) más que 20 euros en el bolsillo

La interpretación cuantitativa que impone la presencia de la preposición de al frente del elemento que funciona como fondo en (42a) obliga a interpretar que la suma se produce entre elementos de la misma especie, de manera que hay que concluir que las otras cosas compradas son ordenadores, restricción que no se da en (42b), donde la interpretación individuativa que introduce que lleva a interpretar que lo comprado incluyó algo más que ordenadores. Algo similar sucede en (43): el contenido proposicional de (43a) alude únicamente a la cantidad de euros que había en el bolsillo, sin implicar que no pudiera haber en él otros objetos (llaves, un pañuelo), mientras que si lo que se quiere expresar es que en el bolsillo había euros y nada más, la única opción es (43b). Nótese que en esta última se puede añadir como diferencial nada, pero no en la primera. Ello se debe a que este cuantificador negativo incorpora léxicamente un restrictor sobre el dominio de entidades que cuantifica, equivalente a "cosa" (de hecho, la oposición entre nada y nadie afecta al restrictor, no al valor cuantificacional de tales unidades). De ahí que nada y nadie no puedan nunca ir acompañados de un nombre (*nada casa, *nadie persona), a diferencia de otros cuantificadores como muchos, pocos, algunos o ningún. Como las aditivas con de sólo pueden sumar cantidades o grados de una misma entidad, resultan incompatibles con estas entidades, que incorporan un restrictor diferente. En cambio, las aditivas cuyo fondo va introducido por que pueden combinarse con ellas, porque tal restricción no se da: nada más que un minuto, nadie más que Pepe.

Supongamos que en (43b) no se incluye el cuantificador negativo nada. En tal caso, la oración pasa a ser ambigua, ya que la interpretación cuantificativa queda activada por la existencia del SCu 20 euros. De modo que es posible proferir esa oración en un contexto en el que haya otras cosas en los bolsillos, a condición de que no aparezca nada en el diferencial.

\section{Las codas de las comparativas propias}

Como se ha señalado, las comparativas de desigualdad pueden adoptar dos variantes. Una diferencia importante entre las comparativas relativas y las propias es que sólo en las primeras es obligatoria la presencia de por lo menos un verbo en forma personal: 
(44) a. Compré más revistas que tú (comparativa propia)

b. *Compré más revistas de las que tú (comparativa relativa).

Esta característica es general para toda clase de subordinadas relativas, por lo que no es necesario añadir ninguna restricción específica que afecte a las que aparecen en las construcciones comparativas. Tampoco es exclusivo de estas últimas la posibilidad de elisión del verbo de la oración que contiene el elemento relativo, a condición - como se ha dicho - de que permanezca en la subordinada alguna forma verbal flexionada de una oración superordinada:

(45) a. Tienen más argumentos de los que creíamos (que tenían) (comparativa)

b. Haré lo que digas (que haga) (no comparativa)

En cambio, es mucho más polémica la naturaleza de las codas de las comparativas propias, dada la gran flexibilidad que presentan. Fundamentalmente, pueden distinguirse dos enfoques: el que defiende el carácter sintagmático y no oracional de tales constituyentes y el que los considera elementos oracionales en los que se han producido en la mayoría de las ocasiones procesos de elisión bajo condiciones de recuperabilidad. Un ejemplo del primer enfoque lo constituye Sáez del Álamo (1999), mientras que Gutiérrez Ordóñez (1994a) opta por un análisis con elipsis. En Brucart (2003) se opta por un análisis mixto, que es el que se expondrá aquí.

Lo primero que conviene tener en cuenta es que algunas codas de comparativas propias son incontestablemente oracionales, como las de (46):

(46) a. He leído más libros yo en mi vida que periódicos ha hojeado Juan en la suya

b. *He leído más libros yo en mi vida que Juan ha hojeado periódicos en la suya

El contraste de gramaticalidad que se da en el par anterior se debe a que en la segunda oración el correlato del $\mathrm{SCu}$ de la primera no ha ascendido a la posición inmediatamente posterior al nexo que. Esta operación de focalización ${ }^{20}$ desencadena, por otra parte, la inversión obligatoria en el orden sujeto-verbo, que es característica del ascenso de las unidades $q u$-. En (46) todos los elementos de la oración que funciona como coda contrastan con su correspondiente correlato en la oración

20 Quizás no se trate propiamente de una focalización, sino de un ascenso para marcar la naturaleza de tópico contrastivo del SCu que funciona como correlato de la entidad comparada. Tal elemento, que forma parte obligatoriamente de la interpretación de toda oración comparativa, ya que es el que denota la cantidad o grado que se toma como base de comparación, aparece elidido en todos los casos en que la comparación se establece entre entidades de la misma clase: He leído más libros que tú, donde la coda se interpreta "que libros has leído tú", con elisión del material coincidente. Si el movimiento del $\mathrm{SCu}$ de la coda fuera a una posición focal, la elisión de este componente sería extraña. No obstante, cabe señalar también que lo que coincide en estos casos es el restrictor del $\mathrm{SCu}$, y nunca la parte cuantificacional. 
matriz: Yo-Juan, he leído- ha hojeado, libros-periódicos, en mi vida- en la suya. Pero es más frecuente que alguno de los términos de la coda coincidan con los de la oración matriz, como en (47). En tal caso, una regla de elisión provoca que no se realice el contenido fonético de los elementos reiterados ${ }^{21}$ :

(47) a. He leído yo más libros la semana pasada que periódicos ha leído Juan ta semana pasada

b. He leído yo más libros la semana pasada que tibros ha lédo Juan ta semana pasada

c. He leído más libros la semana pasada que tibros té la anterior

Por lo tanto, dos parecen ser los mecanismos que se aplican en las codas oracionales de las comparativas de desigualdad: (a) la focalización (o topicalización contrastiva) del elemento cuantificado de la coda y (b) la elisión del material repetido. Este borrado de la información repetida tiene efectos fonéticos, pero en ningún caso semánticos. Así, pese a que no aparece fonéticamente realizado, la interpretación de la coda comparativa de $(47 \mathrm{~b}, \mathrm{c})$ tiene que contar necesariamente con el constituyente focalizado libros, ya que es esta clase de objetos lo que se somete a comparación (o, dicho en los términos de nuestro análisis, a adición). De lo contrario, tendríamos que suponer que la coda de $(47 \mathrm{~b})$ remite únicamente a un individuo o que la de (47c) denota un intervalo temporal, nociones que no corresponden a la clase de magnitud comparada en tales oraciones.

Es interesante comprobar que otras lenguas románicas cuentan con una estrategia diferente a la del ascenso del elemento focalizado característica del español: la presencia de una negación expletiva. Tal es el caso del francés, como muestran los ejemplos de (48), extraídos de Price (1990: 93):

(48) a. ?Le travail est plus difficile que détaillé est le contrat

b. *Le travail est plus difficile que détaillé n'est le contrat.

c. Le travail est plus difficile que le contrat n'est detaillé.

Parece plausible suponer que la función que desempeña la negación expletiva en estos casos es la de marcador de foco a distancia del elemento de grado que constituye el segundo término de la comparación. En español sólo es posible una negación expletiva cuando se ha producido elisión de material en la subordinada: Más vale maña que no fuerza.

21 Como muestra (47c), la regla de elisión no exige identidad total en algunos casos, tal como sucede en otras construcciones de esta naturaleza, como el vaciado: Yo juego al tenis y tú juegas al golf, donde el antecedente y forma elidida divergen en persona. Sobre un análisis de estos fenómenos en términos de la morfología distribuida, cfr. Saab (2008). 
Para concluir, trataremos los casos en que el único material que aparece en la coda comparativa es el SCu que funciona como correlato de la entidad comparada. Se trata de ejemplos como (49):

(49) a. Ha leído más periódicos que libros

b. Más estudiantes que profesores asistieron a la reunión

c. He visto bastantes más películas que esas

Una particularidad importante de estas comparativas es que la coda puede aparecer delante del predicado, acompañando al primer término de la comparación, como se muestra en (49b). Por otra parte, no parece posible proponer un contenido proposicional para la coda de (49c) en la variante comparativa (es decir, aquella en la que el demostrativo se interpreta cuantificativamente). Una manera de reflejar la mayor flexibilidad posicional de estas construcciones consiste en suponer que en este caso el contenido de la coda es sintagmático y no oracional. Por lo tanto, en estos casos no parece necesario recurrir a la idea de que se han producido mecanismos de elisión de material, sino que basta suponer que el esquema que se aplica es el mismo que permite formar las construcciones aditivas no comparativas que hemos estudiado en la primera parte del trabajo. La presencia de que en lugar de de en estos ejemplos viene impuesta por el hecho de que se están sumando cardinalidades de entidades distintas. A su vez, la interpretación comparativa deriva del hecho de que los miembros que entran en la construcción aditiva vectorial se interpretan cuantitativamente.

\section{Conclusiones}

En este trabajo hemos intentado defender los siguientes supuestos:

1. Más presenta un conjunto de usos en español que responden a un único valor como operador aditivo binario.

2. La distinción entre el más simétrico y el asimétrico deriva de la presencia en la proyección de este último de una serie de proyecciones funcionales que dan lugar a una construcción vectorial formada por un fondo y una figura que se interpreta como diferencial

3. Existen procedimientos que permiten recuperar tanto el fondo como el diferencial de la construcción vectorial. Sin embargo, ambos componentes deben tenerse en cuenta en la interpretación de estas construcciones.

4. Las comparativas de desigualdad son un caso particular de construcción vectorial encabezada por más o menos. La coda comparativa representa la magnitud que se toma como fondo de la construcción vectorial.

5. Frente a lo que parece sugerir la etiqueta de "comparativas", en tales construcciones el diferencial es un elemento primitivo y no derivado. 
6. La particularidad que presentan las oraciones comparativas respecto de otras construcciones aditivas no comparativas consiste en que la base de comparación puede tener carácter proposicional y que los elementos que entran en la relación vectorial pueden pertenecer a entidades distintas.

7. La alternancia $d e$ - que en la introducción del elemento que se concibe como base o fondo de estas construcciones tiene que ver con la naturaleza cuantitativa o individuativa del correspondiente complemento. En las comparativas, el uso de de queda limitado a aquellas cuya coda adopta la forma de una relativa cuantitativa, seguramente porque los rasgos del relativo se proyectan a la raíz de la construcción, dando lugar a un $\mathrm{SCu}$ o SG, tal como propone Donati (2006). En cambio, pese a contar con un elemento focalizado, las codas oracionales de las comparativas propias son SC, por lo que se combinan con que.

8. Si el análisis presentado en este trabajo es correcto, las construcciones vectoriales aditivas constituyen un caso interesante de argumento en favor de la autonomía de la forma sobre la función lingüística, ya que muestran que una noción cognitiva como la de comparación se codifica lingüísticamente a través de un patrón formal más básicos, como es el aditivo-sustractivo vectorial.

\section{Referencias bibliográficas}

Andersen, P. K. (1983): Word Order Typology and Comparative Constructions. Amsterdam, Benjamins.

Bello, A. (1841): Análisis ideológica de los tiempos de la conjugación castellana. Valparaíso, Imprenta de M. Rivadeneyra. Reed. en Bello, A. (1951): Obras completas, V. Estudios gramaticales, Caracas, Ministerio de Educación, págs. 3-67.

Borer, H. (2005): Structuring sense, vol 1: In the name only. Oxford, Oxford University Press.

Bošković, Ž. and D. Takahashi (1998): "Scrambling and Last Resort". Linguistic Inquiry, 29 , págs. 347-366.

Bosque, I. (1984): "Sobre la sintaxis de las oraciones exclamativas", Hispanic Linguistics, 1, págs. 283-304.

Bosque, I. (1999): "El sintagma adjetival. Modificadores y complementos del adjetivo. Adjetivo y participio". En I. Bosque \& V. Demonte (eds.), págs. 217-310.

Bosque, I. y V. Demonte (eds.) (1999): Gramática descriptiva de la lengua española. Madrid, Espasa Calpe.

Brucart, J. M. (1993): “Sobre la estructura de SComp en español”. En Viana, Amadeu (ed.), Sintaxi. Teoria i perspectives. Lleida, Pagès, págs. 59-102.

Brucart, J. M. (2003): “Adición, sustracción y comparación: un análisis composicional de las construcciones aditivo-sustractivas del español”. En Sánchez Miret, F. (ed.), Actas del XXIII Congreso Internacional de Lingüística y Filología Románica. Tübingen, Max Niemeyer, págs. 11-60.

Brucart, J. M.; A. Gavarró, \& J. Solà (2009): "Merging features: a minimalist introduction". En Brucart, J. M.; A. Gavarró, \& J. Solà (eds.), Merging Features: Computation, Interpretation and Acquisition. Oxford, Oxford University Press, 2009, págs. 1-22. 
Bull, W. (1960): Time, tense, and the verb. A study in theoretical and applied linguistics with particular attention to Spanish. Berkeley, University of California Press.

Chomsky, N. (2004): "Beyond explanatory adequacy". En Belletti, Adriana (ed.), Structures and beyond. Oxford, Oxford University Press, págs. 104-131.

Chomsky, N. (2005): 'Three Factors in Language Design'. Linguistic Inquiry 36.1, págs. $1-22$.

Corbett, G. G.; Norman S. Fraser, \& Scott McGlashan (eds.) (1993): Heads in Grammatical Theory. Cambridge, Cambridge University Press.

Cuenca, M. J. y J. Hilferty (1999): Introducción a la lingüística cognitiva. Barcelona, Ariel.

Eguren, L. y O. Fernández Soriano (2004): Introducción a una sintaxis minimista. Madrid, Gredos.

Escandell Vidal, M. V. (2004): Fundamentos de semántica composicional. Barcelona, Ariel.

Donati, C. (2000): La sintassi della comparazione, Padova, Unipress.

Donati, C. (2006): "On Wh-head-movement". En Cheng, L. \& N. Corver (eds.), Wh-Movement: Moving on. Cambridge (Mass.), MIT Press, págs. 21-46.

Gallego, Á. y R. González (2005): A lexical syntax for comparatives. Ponencia en ConSOLE $X I V$ (www.ehu.es/console/Abstracts/Gallego\&Gonzalez.pdf)

Giorgi, A. \& G. Longobardi (1991): The Syntax of Noun Phrases. Configuration, Parameters and Empty Categories. Cambridge, Cambridge University Press.

Goldberg, A. E. (1995): Constructions: a construction grammar approach to argument structure. Chicago, University of Chicago Press.

Grice, H. P. (1975): "Logic and Conversation". En Cole, P. \& J. Morgan (eds.), Speech Acts (Syntax and Semantics, 3). New York, Academic Press, págs. 41-58.

Gutiérrez Ordóñez, S. (1992): "Más de - Más que”, Contextos, X/19-20, págs. 47-86. Cito por la reed. En Gutiérrez Ordóñez, S. (1997): La oración y sus funciones. Madrid, Arcolibros, págs. 520-548.

Gutiérrez Ordóñez, S. (1994a): Estructuras pseudocomparativas. Madrid, Arcolibros.

Gutiérrez Ordóñez, S. (1994b): Estructuras comparativas. Madrid, Arcolibros.

Hale, K. (1986): "Notes on World View and Semantic Categories: some Warlpiri Examples". En Muysken, P. \& H. van Riemsdijk (eds.), Features and Projections. Dordrecht, Foris, págs. 233-254.

Halle, M. \& A. Marantz (1994): "Some key features of Distributed Morphology". En Carnie, A. \& H. Harley: Papers on phonology and morphology (MITWPL, 21). Cambridge (Mass.), MIT, págs. 275-288.

Harley, H. (1995): Subjects, Events, and Licensing. Tesis doctoral, MIT.

Hoecksema, J. (1984): "To be continued: the story of the comparative", Journal of Semantics, 3, págs. 93-107.

Horn, L. R. (1996): “Presupposition and Implicature”. En Lappin, S. (ed.), The Handbook of Contemporary Semantic Theory. Oxford, Blackwell, págs. 299-319.

Hornstein, N. (2001): Move! A Minimalist Theory of Construal. Oxford, Blackwell.

Izvorski, R. (1995): “A DP-shell for comparatives”, Console III Proceedings, págs. 99121.

Kayne, R. S. (1994): The Antisymmetry of Syntax. Cambridge (Mass.), MIT Press. 
Matushansky, O. (2006): "Head Movement in Linguistic Theory", Linguistic Inquiry, 37, págs. 69-109.

Mendívil Giró, J. L. (2003): Gramática natural: la gramática generativa y la tercera cultura. Madrid, Antonio Machado.

Newmeyer, F. J. (1998): Language Form and Language Function. Cambridge (Mass.), MIT Press.

Plann, S. (1982): “Indirect Questions in Spanish”, Linguistic Inquiry 13, págs. 297-312.

Plann, S. (1984): “Cláusulas cuantificadas”, Verba 11, págs. 101-128.

Price, S. (1990): Comparative Constructions in Spanish and French Syntax. London, Routledge.

Rojo, G. (1974): “La temporalidad verbal en español”. Verba, 1, págs. 68-149.

Saab, A. (2008): Hacia una teoría de la identidad parcial en la elipsis. Tesis doctoral, Universidad de Buenos Aires.

Sáez del Álamo, L. (1997): "Cuantificadores y sintagmas de medida”. En Català, N. \& M. Bargalló (eds.), Proceedings of the IV colloquium on generative grammar. Tarragona, Universitat Rovira i Virgili, págs. 162-186.

Sáez del Álamo, L. (1999): "Los cuantificadores: las construcciones comparativas y superlativas", en I. Bosque \& V. Demonte (eds.), págs. 1129-1188.

Stassen, L. (1985): Comparison and Universal Grammar. Oxford, Blackwell.

Svenonius, P. (en prensa): "Spatial P in English". En Cinque, G. \& L. Rizzi (eds.): Mapping Spatial PPs. The Cartography of Syntactic Structures, vol. 6. New York, Oxford University Press.

Zubizarreta, M. L. (1998): Prosody, Focus, and Word Order. Cambridge (Mass.), MIT Press.

Zwarts, J. (1997): "Vectors as relative positions: A compositional semantics of modified PPs", Journal of Semantics, 14, 57-86.

Zwarts, J. \& Y. Winter (2000): "Vector space semantics: A model-theoretic analysis of locative prepositions", Journal of Logic, Language and Information, 9, 171-213. 
